\title{
Refrigerant selection for ejector refrigeration systems: a multiscale evaluation
}

\author{
Giorgio Besagni ${ }^{1,}{ }^{*}$, Lorenzo Croci $^{1}$, Nicolò Cristiani ${ }^{1,2}$, Gaël Raymond Guédon ${ }^{2}$, and Fabio \\ Inzoli $^{2}$ \\ ${ }^{1}$ Ricerca sul Sistema Energetico - RSE S.p.A., Power System Development Department, via \\ Rubattino 54, 20134 Milano, Italy \\ ${ }^{2}$ Politecnico di Milano, Department of Energy, via Lambruschini 4a, 20156, Milano, Italy
}

\begin{abstract}
The selection of refrigerants for ejector refrigeration systems, within the broader discussion concerning refrigerant phase-out, is a cutting-edge and challenging research topic, owing to the multi-scale challenges in ejector performance. Indeed, it is known that the performances of ejector refrigeration systems depend on the local flow phenomena. For this reason, a precise selection of the refrigerant relies on the understanding of the fluid dynamic phenomena at the "componentscale", and integrate such information within the so-called "system-scale". This paper contributes to the current discussion proposing a screening of refrigerants based on an integrated Computational Fluid Dynamic $(C F D)$ Lumped Parameter Model (LPM) approach. In this approach, ejector performances for the different refrigerant are obtained by a validated $C F D$ approach, whereas the cycle is modelled by a Lumped Parameter Model. For the different refrigerants, the energy performances of the systems are evaluated and the effects of the "component-scale" on the "system-scale" are analysed.
\end{abstract}

\section{Introduction}

Ejector device is a static component, where an high-pressure stream ("primary flow") accelerates till sonic/supersonic condition while flowing into a converging/convergingdiverging nozzle and, subsequently, expands into a mixing chamber while entraining a lowpressure stream ("secondary flow"); the primary and the secondary flows mix and are compressed in a diffuser [1]. An ejector provides three effects (entrainment, mixing and compression), making it suitable in refrigeration systems. On one hand, ejector refrigeration systems (ERSs, Figure 1a - forthcoming nomenclature refers to this figure) pose as a promising alternative compared with compressor-based systems owing to limited maintenance, low cost, no working fluid limitation and the possibility to exploit low-grade thermal energy sources. On the other hand, ERSS suffer from low coefficient of performance $(C O P)$, generally in the range of 0.1 - 0.7 (see ref. [1]). Moreover, COP depends on the ejector-component performance, which is determined by the local-scale flow phenomena; in turn, the flow phenomena are imposed by the ejector design,

${ }^{*}$ Corresponding author: giorgio.besagni@, rse-web.it 
refrigerant properties and inlet/outlet boundary conditions [2,3]. For the sake of clarity, a discussion regarding ejector-component performance is proposed, based on the ejector operating curve (Figure $1 \mathrm{~b}$ - note that Figure $1 \mathrm{~b}$ is valid under the assumption of $T_{3}$ in saturation conditions), which displays the relationship between the entrainment ratio $(\omega$, Eq. (1)) and the outlet boundary conditions (saturation $T_{3}$ ). In on-design operation mode, $\omega$ is constant, as the primary and the secondary flows are in supersonic conditions [2]; conversely, when the outlet conditions reaches a critical point $\left(T_{3}=T_{c r i t}\right)$, the secondary flow is no more chocked, and $\omega$ decreases while $T_{3}$ increases.

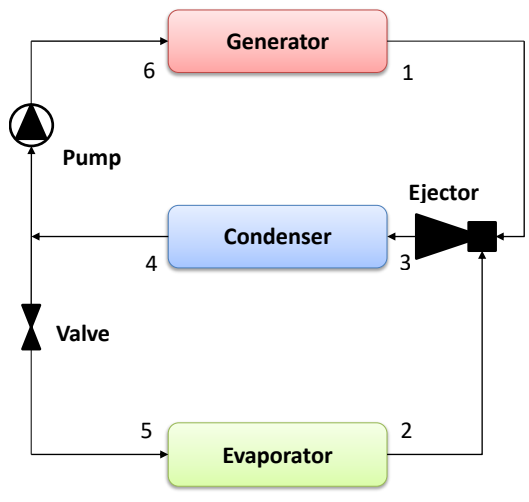

(a) ERS

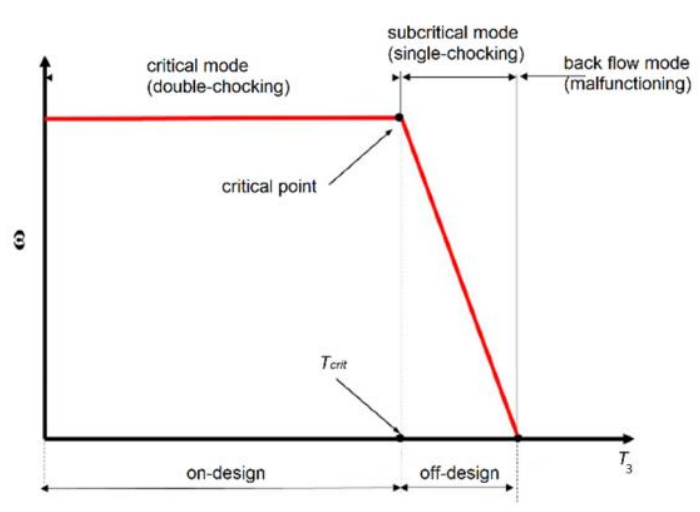

(b) Ejector operating curve

Fig. 1. Ejector refrigeration system: system-scale (s) and component-scale (b) behavior.

As rule of thumb, a change in ejector design and/or refrigerant change $T_{\text {crit }}$ coordinates, whereas the boundary conditions impose the operating point on the operating curve. Based on the definition of $C O P$ (Eq. (2)), it is clear how the ejector-component performance is related to the $E R S$ performance:

$$
\begin{gathered}
\omega=\frac{\dot{\mathrm{m}}_{2}}{\dot{\mathrm{m}}_{1}} \\
\mathrm{COP}=\frac{\dot{\mathrm{m}}_{2}}{\dot{\mathrm{m}}_{1}} \frac{\mathrm{h}_{2}-\mathrm{h}_{5}}{\mathrm{~h}_{1}-\mathrm{h}_{6}} \underbrace{\omega}_{\mathrm{Eq} \cdot(1)} \omega \frac{\mathrm{h}_{2}-\mathrm{h}_{5}}{\mathrm{~h}_{1}-\mathrm{h}_{6}}
\end{gathered}
$$

Where $\dot{m}$ is the flow rate and $h$ is enthalpy. In the broader framework of ejector research, this paper contributes to the present-day discussion regarding multi-scale modeling approaches, linking the "local-scale" to the "system-scale" and it focuses on the selection of suitable refrigerants for different ejector designs. This particular topic is attracting a growing discussion given the international regulations [4] aiming to phasing-out some of the commonly used fluids (viz., hydrofluorocarbons, $H F C$ - i.e., R134a, R245fa, R152a), pointing towards possible replacements (viz., hydrofluoroolefins, $H F O$ - i.e., R1132a, R1123, R1234yf, R1243zf, R1234ze, R1224yd, R1233zd, R1336mzz [5]). Yadav et al. [6] $\left(T_{2}=5^{\circ} \mathrm{C}, T_{3}=40^{\circ} \mathrm{C}\right)$ proposed a lumped-parameter study of an ejector-expansion refrigeration cycle operated with R134a, R1234yf and R1234ze; they found that R1234ze is characterized by the highest COP, followed by R134a and R1234yf. Chen et al. [7] $\left(T_{1}=\right.$ $95^{\circ} \mathrm{C}, T_{2}=10^{\circ} \mathrm{C}, T_{3}=35^{\circ} \mathrm{C}$ ) proposed a lumped-parameter study of an $E R S$, operated with nine refrigerant; R245fa and R600 showed the best performances $(C O P=0.38)$, followed by R600a $(C O P=0.35), \mathrm{R} 1234 \mathrm{ze}(C O P=0.33), \mathrm{R} 134 \mathrm{a}$ and $\mathrm{R} 430 \mathrm{~A}(C O P=0.28), \mathrm{R} 152 \mathrm{a}$ and R290 $(C O P=0.25), \mathrm{R} 438 \mathrm{~B}(C O P=0.18)$. Fang et al. [8] proposed a Computational Fluid-Dynamics (CFD) study for the drop-in replacement of R134a in an ERS; they found that $\mathrm{R} 134 \mathrm{a}$ has the highest $C O P$; its replacement with R1234ze and R1234yf reduces $C O P$ 
of approximately $4.2 \%$ and $9.6 \%$, respectively. The present study considers three ejector geometries (changing the nozzle exit position from a baseline case) and compared fourth generation/natural refrigerants (R1234yf, R1234ze, R1233zd, R290, R600a R1270) with commonly used refrigerants (R134a, R245fa, R152a): for the different cases, ejector operating curves are obtained and compares. A brief overview of the tested refrigerants is presented in Figure 2. This paper proceeds as follows. Section 2 describes the numerical methods and benchmark, Sections 3 presents the results and Section 4 outlines the conclusions.

\section{Methods}

\subsection{Numerical modelling}

The finite volume code ANSYS Fluent (Release $2020-R 1$ ) has been used to solve the steady state Reynolds Averaged Navier-Stokes (RANS) equations for the turbulent compressible Newtonian flow. This study employs the $k-\omega S S T$ model, which was found the most suitable turbulence model in ref. [10].

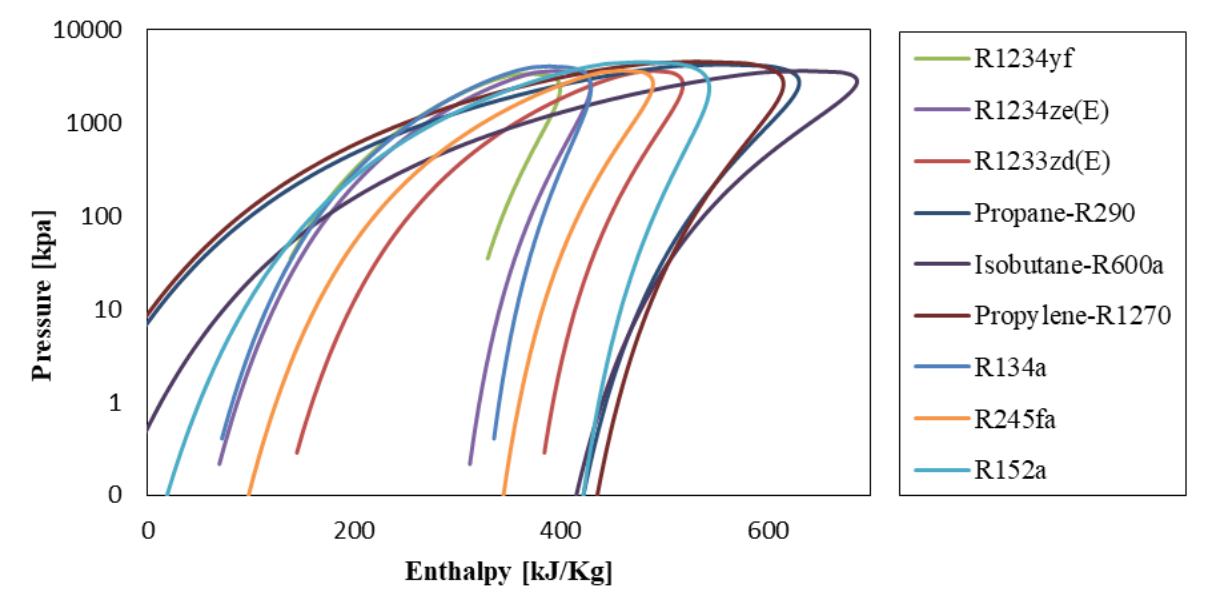

Fig. 2. $P$ - $h$ representation of the tested refrigerants - property evaluated based on ref. [9].

Turbulence boundary conditions are implemented as follows: hydraulic diameter and the turbulent intensity (5\% for the primary flows and $2 \%$ for the secondary one), as described in ref. [10]. Second order upwind numerical schemes have been used for the spatial discretization, in order to limit the numerical diffusion. Second order upwind schemes also for the turbulence model variables have been used. Gradients are evaluated by a least-squares approach. The initialization has been performed by a two-step approach: (i) an hybrid initialization followed by a (ii) full multi-grid $(F M G)$ scheme. The numerical solution is considered as converged when the normalized difference of mass flow rates at the inlets and at outlet is less than $10^{-5}$ and the mass flow-rate variation of primary and secondary flow on the last 50 iterations is less than $10^{-5}$. Pressure-based solver has been adopted accordingly with ref. [8], providing close results compared with density-based solver but with faster convergence and higher stability. As for the geometrical modeling, a $2 D$-axial symmetric structured mesh is built as follows: (i) maximum aspect ratio of 3; (ii) $y^{+}$in the range of $30-200$; (iii) two cycles of refinement based on Mach gradient criterion 
(scaled on global maximum more than 0.1) have been applied during the simulations. Fluid properties have been evaluated with the real-gas NIST database [11].

\subsection{Benchmark}

The numerical model has been validated against a baseline case provided by Del Valle et al. [12], whose geometry and boundary are presented in Figure 3 and Table 1. It is worth noting that in ref. [12], both global ( $\omega$, entrainment ratio) and local (wall static pressure along the ejector) measurements are available.

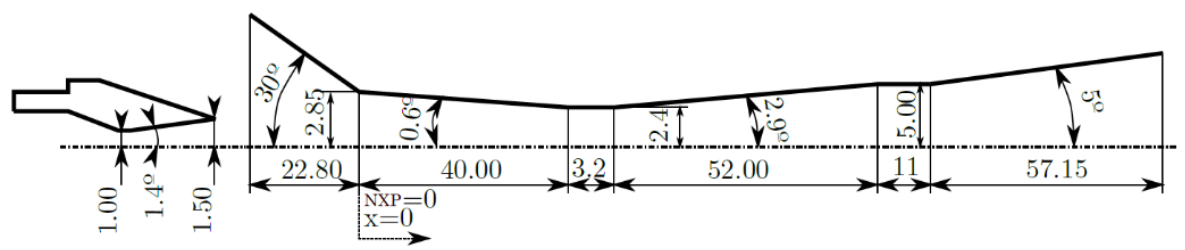

Fig. 3. Ejector design from ref. [12]; dimensions in [mm].

Table 1. Boundary conditions for the validation case.

\begin{tabular}{ccccccc}
\hline $\boldsymbol{T}_{\boldsymbol{1}}$ & $\boldsymbol{P}_{1}[\mathrm{~Pa}]$ & $\begin{array}{c}\boldsymbol{T}_{\boldsymbol{2}} \\
{\left[{ }^{\circ} \mathbf{C}\right]}\end{array}$ & $\boldsymbol{P}_{2}[\mathrm{~Pa}]$ & $\begin{array}{c}\boldsymbol{T}_{3} \\
{\left[{ }^{\circ} \mathbf{C}\right]}\end{array}$ & $\boldsymbol{P}_{3}[\mathbf{P a}]$ & $\begin{array}{c}\text { Nozzle exit position }(\boldsymbol{N X P}) \\
{[\mathbf{m m}]}\end{array}$ \\
\hline 84.2 & $2,330,000$ & 20 & 415,000 & 24.22 & 650,000 & -4.37 \\
\hline
\end{tabular}

The experimental and numerical results are compared based on Eq. (3), regarding the entrainment, and Eq. (4), for the $N$-data composing the local pressure profiles:

$$
\begin{gathered}
\text { Relative error }=\frac{\omega_{\text {CFD }}-\omega_{\text {ref. [12] }}}{\omega_{\text {ref. [12] }}} \\
\text { Mean absolute error }=\frac{1}{N} \sum_{\mathrm{i}=1}^{N} \frac{\left|\mathrm{p}_{\mathrm{CFD}, \mathrm{i}}-\mathrm{p}_{\text {ref. [12],i }}\right|}{\mathrm{P}_{\text {ref. [12],i }}}
\end{gathered}
$$

\subsection{Screening of refrigerants}

The screening of refrigerants has been performed for the fluids listed within Figure 2, for fixed operating conditions: $T_{1}=84.2^{\circ} \mathrm{C}\left(10^{\circ} \mathrm{C}\right.$ superheating $)$ and $T_{2}=14^{\circ} \mathrm{C}\left(4^{\circ} \mathrm{C}\right.$ superheating). For the given inlet conditions, different outlet conditions will be tested, so to obtain the ejector operating curves and to compare the critical conditions. This screening allows comparing the refrigerant performances for given generator and evaporator temperature conditions, changing for pressure levels to match these specifications. As mentioned in the introduction, three ejector geometries with different nozzle exit positions have been tested, as summarized in Table 2. Starting from the benchmark case (Geom\#1), two other geometries are obtained increasing and decreasing the nozzle exit value, accordingly with ref. [13]. A summary of all tested cases, for the different ejector design and refrigerants, is proposed in Table 3. 
Table 2. Tested NXP and relative code name.

\begin{tabular}{cc}
\hline Case & NXP $[\mathbf{m m}]$ \\
\hline Geom\#1 - Benchmark case & -4.37 \\
Geom\#2 & -1.7 \\
Geom\#3 & -7.05 \\
\hline
\end{tabular}

Table 3. Boundary conditions and list of the simulated cases [9].

\begin{tabular}{|c|c|c|c|c|c|c|c|}
\hline \multicolumn{2}{|c|}{ Code name } & \multirow[b]{2}{*}{$\boldsymbol{T}_{1}\left[{ }^{\circ} \mathrm{C}\right]$} & \multirow[b]{2}{*}{$P_{1}[\mathrm{kPa}]$} & \multirow[b]{2}{*}{$\boldsymbol{T}_{2}\left[{ }^{\circ} \mathrm{C}\right]$} & \multirow[b]{2}{*}{$P_{2}[\mathrm{kPa}]$} & \multirow[b]{2}{*}{$\mathrm{T}_{3}\left[{ }^{\circ} \mathrm{C}\right]$} & \multirow[b]{2}{*}{$P_{3}[\mathrm{kPa}]$} \\
\hline $\begin{array}{c}N X P \\
\text { (Table 2) }\end{array}$ & Refrigerant & & & & & & \\
\hline \multirow{9}{*}{ Geom\#1, 2, 3} & R1234yf & 84.2 & $2,241.1$ & 14 & 437.5 & $22-26.5$ & $626.9-711.8$ \\
\hline & R1234ze & 84.2 & $1,774.8$ & 14 & 308.3 & $22-27$ & $454.8-529.3$ \\
\hline & R1233zd & 84.2 & 571.4 & 14 & 73.4 & $23-29.5$ & $120.8-152.1$ \\
\hline & R290* & 84.2 & $2,813.5$ & 14 & 636.6 & $21-25$ & $858.7-952.1$ \\
\hline & $\mathrm{R} 600 \mathrm{a}^{* *}$ & 84.2 & $1,193.9$ & 14 & 220.6 & $23-26.5$ & $330.6-366.3$ \\
\hline & $\mathrm{R} 1270$ *** & 84.2 & $3,346.5$ & 14 & 778.6 & $21-25$ & $1,043.5-1,154.4$ \\
\hline & R134a & 84.2 & $2,330.3$ & 14 & 414.6 & $22-27$ & $607.9-705.9$ \\
\hline & R245fa & 84.2 & 683.0 & 14 & 82.4 & $23-30$ & $137.9-178.1$ \\
\hline & R152a & 84.2 & $2,075.2$ & 14 & 372.8 & $22-27$ & $545.1-632.5$ \\
\hline
\end{tabular}

* Propane

** Isobutane

**** Propylene

\subsection{Multi-scale modelling}

Ejector performances for the different refrigerant are obtained by the $C F D$ approach described above whereas the ERS is modelled by a Lumped Parameter Model. To relate $C F D$ results (ejector flow phenomena and ejector performances) to the ERS performance, the procedure discussed in ref. [8] is used. This method relies on the following assumptions: no pressure losses, isenthalpic valve and pump isentropic efficiency equal to $90 \%$. Thus, for all the tested cases (Table 3) the ejector performance $\omega$ (Eq. (1)) is related to the ERS performance, in terms of COP (Eq. (2)) and $\dot{\mathrm{Q}}_{\text {evaporator }}$ (Eq. (5)):

$$
\dot{\mathrm{Q}}_{\text {evaporator }}=\dot{\mathrm{m}}_{2}\left(\mathrm{~h}_{2}-\mathrm{h}_{5}\right)
$$

In addition, for all the ejector operating curves, the critical conditions are estimated as the intersection between a linear interpolation of points in the on-design and off-design operation modes.

\section{Results and discussion}

\subsection{Validation}

The validation procedure of the $C F D$ model against above-presented benchmark [12] showed a fair agreement between experimental data and the numerical outcomes in term of global $\left(\omega_{C F D}=0.695\right.$; relative error equal to $\left.17.4 \%\right)$ and local (Figure 4 - mean absolute error equal to $4.8 \%$ ) data. 


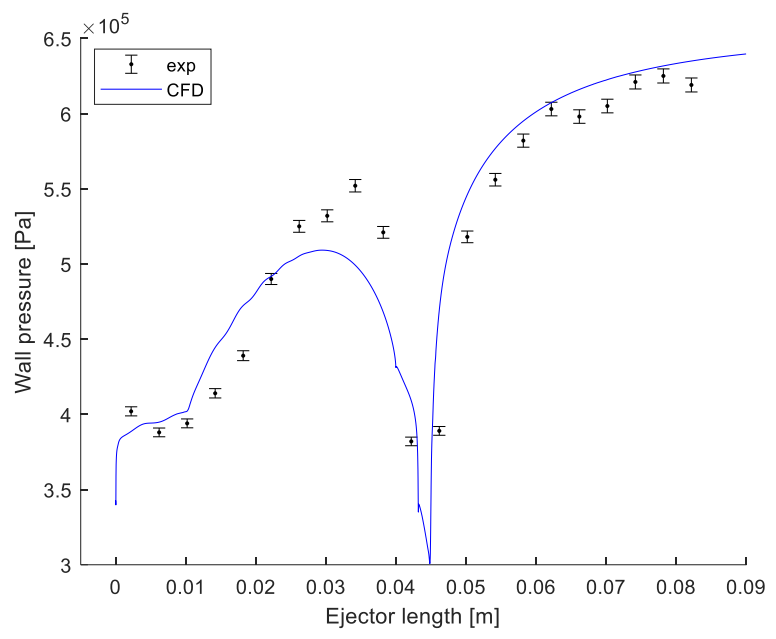

Fig. 4. Numerical model validation: wall static pressure profile in ref. [12] $\left(T_{1}=84.2^{\circ} \mathrm{C}, P_{1}=\right.$ $\left.2,330,000, \mathrm{~Pa} T_{2}=20.0^{\circ} \mathrm{C}, P_{2}=415,000 \mathrm{~Pa}, P_{3}=650,00 \mathrm{~Pa}\right)$.

\subsection{Screening of refrigerants}

The outcomes of the refrigerant screening are proposed in Table 4, for all the tested cases; conversely, $\omega$ and COP operating curves for Geom\#2 are presented in Figure 4 and Figure 5 , respectively. Finally, Figure 6 displays the Mach contours for Geom\#2 (propane as refrigerant) and Figure 8 proposed the thermodynamic diagrams for Geom\#2 (propane) corresponding cycle $\left(T_{1}=84.2^{\circ} \mathrm{C}, P_{1}=2,813,532 \mathrm{~Pa} T_{2}=14.0^{\circ} \mathrm{C}, P_{2}=636,601 \mathrm{~Pa} T_{3}=\right.$ $23^{\circ} \mathrm{C}, P_{3}=904,508 \mathrm{~Pa}$ ). In the on-design mode, $\omega$ and $C O P$ are both constant up to the critical condition. This behavior is also clear when looking at the local flow phenomena in Figure 6. In the on-design operation mode (Figure $6 \mathrm{a}, \mathrm{b}, \mathrm{c}$ ), the primary flow is able to entrain the secondary flow and promote mixing; the mixed flow entering the diffuser exhibits a shock wave (which becomes weaker approaching the critical point). Such shock wave is also the reason why the ejector performance is not affected by outlet conditions in on-design operation mode. Increasing $T_{3}$ above the critical value (Figure $6 \mathrm{f}$, e) influences the flow phenomena disrupting mixing. In this condition, the primary flow is chocked $\left(\dot{m}_{1}\right.$ does not change), whereas $\dot{\mathrm{m}}_{2}$ decreases while increasing $T_{3}$.

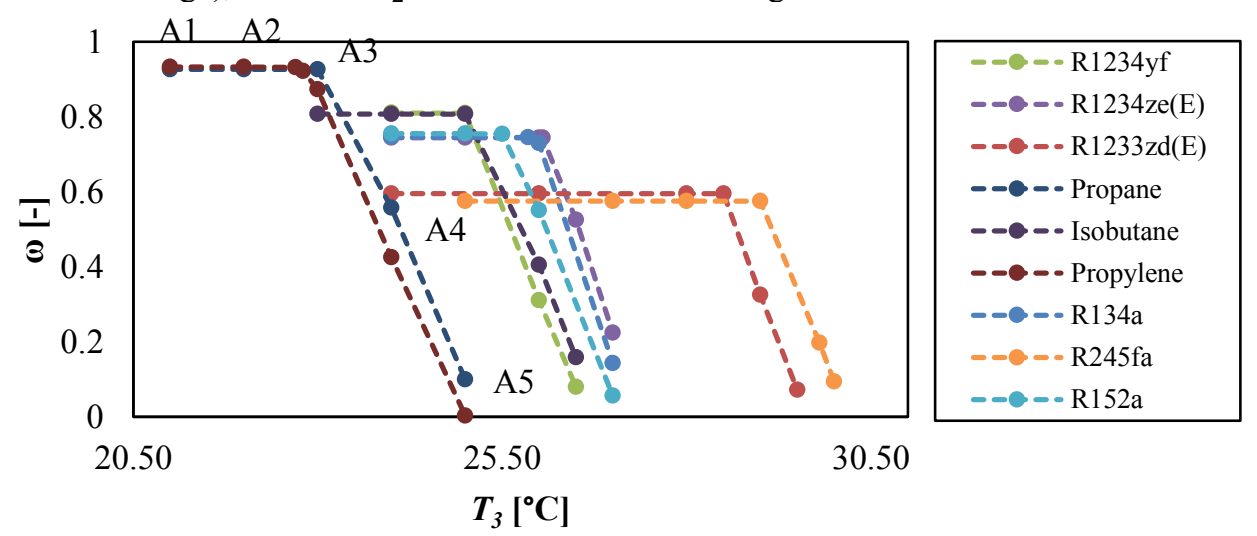

Fig. 5. Ejector operating curve $(\omega)$ for Geom\#2. 


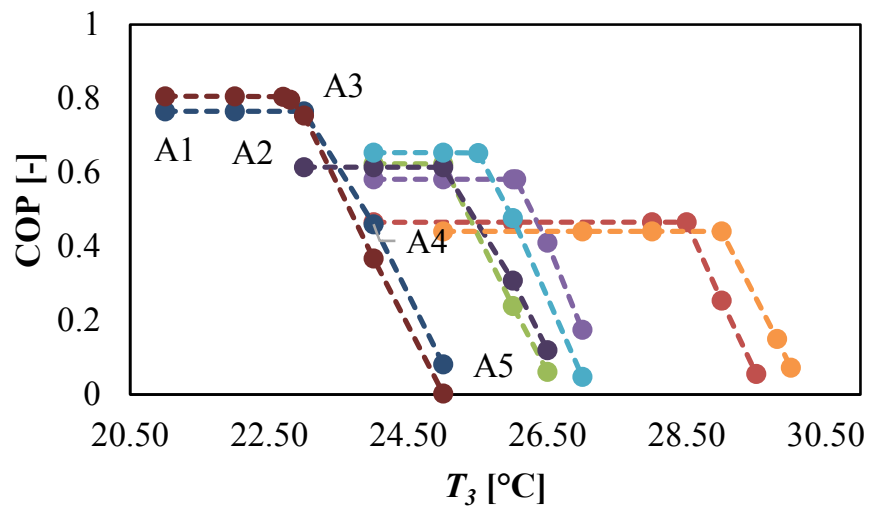

$-\infty-\cdot \mathrm{R} 1234 \mathrm{yf}$

- - - R1234ze(E)

- - - R1233zd(E)

- - - Propane

--c-- Isobutane

- - - Propylene

$-0--\mathrm{R} 134 \mathrm{a}$

$-0--\mathrm{R} 245 \mathrm{fa}$

$--0--\mathrm{R} 152 \mathrm{a}$

Fig. 6. ERS operating curve (COP) for Geom\#2.

(a) $A 1-O n$ design operation mode $\left(T_{3}=21.0^{\circ} \mathrm{C}\right)$

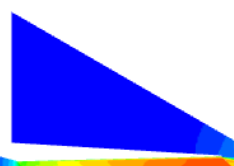

(b) $\mathrm{A2}-$ On design operation mode $\left(\mathrm{T}_{3}=22.0^{\circ} \mathrm{C}\right)$

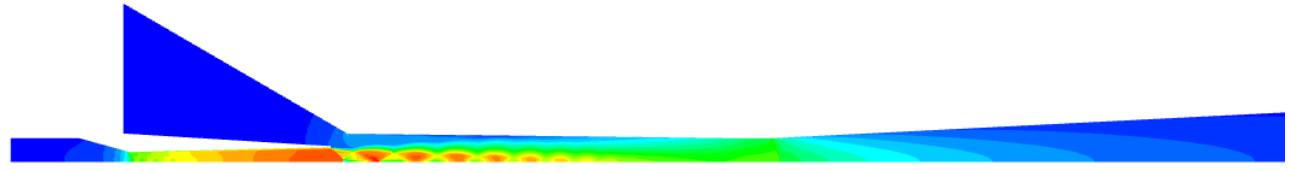

(c) A3-Critical point $\left(T_{3}=23.0^{\circ} \mathrm{C}\right)$

(d) $A 4-$ Off design operation mode $\left(T_{3}=24.0^{\circ} \mathrm{C}\right)$

(e) $A 5$ - Off design operation mode $\left(T_{3}=25.0^{\circ} \mathrm{C}\right)$

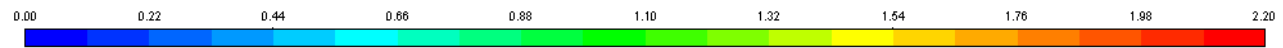

Fig. 7. The ejector "local-scale" (Geom\#2 - Propane): Mach contours $\left(T_{1}=84.2^{\circ} \mathrm{C}, P_{I}=2,813,532\right.$ $\left.\mathrm{Pa} T_{2}=14.0^{\circ} \mathrm{C}, P_{2}=636,601 \mathrm{~Pa}\right)-$ Code names as in Figure 5 and Figure 6.

Looking at Table 4, it is clear that reducing the nozzle exit position, increases both $\omega$ (and $C O P$ ) and $T_{\text {crit }}$, expanding the on-design operation range of the ejector: thus, Geom\#2 $(N X P=-1.7 \mathrm{~mm})$ exhibits the highest performance. Considering the operating curves in 
Figure 4 and Figure 5, three main classes of refrigerants are identified. Compared with R134a, propane and propylene showed higher COP $(+26.6 \%)$, but lower $T_{\text {crit }}(-11.8 \%)$. Fourth generation refrigerants as R1234yf and R1234ze and Isobutane are candidates as $H F C$ replacement, having similar performances compared with R134a and R152a. R1233zd showed the widest operation range ( $T_{\text {crit }}$ is $+10.0 \%$ higher compared with $\mathrm{R} 134 \mathrm{a}$ ) but lower COP (-24.2\% compared with R134a).

Table 4. Summary of ejector and system performances.

\begin{tabular}{llcccc} 
Code name (refer to Table 2) & $\boldsymbol{T}_{\text {crit }}\left[{ }^{\circ} \mathbf{C}\right]$ & $\boldsymbol{C O P}[-]$ & $\omega[-]$ & $\dot{Q}_{\text {evaporator }}[\mathbf{k W}]$ \\
\hline R1234yf & 24.7 & 0.59 & 0.762 & 3.26 \\
R1234ze(E) & 25.7 & 0.54 & 0.696 & 2.61 \\
R1233zd(E) & 28.0 & 0.42 & 0.538 & 0.74 \\
Geom 1 1 Propane & 22.8 & 0.73 & 0.881 & 7.10 \\
& Isobutane & 24.8 & 0.58 & 0.758 & 2.62 \\
& Propylene & 22.5 & 0.77 & 0.889 & 8.65 \\
R134a & 25.4 & 0.58 & 0.699 & 3.64 \\
R245fa & 28.9 & 0.40 & 0.515 & 0.85 \\
R152a & 25.0 & 0.61 & 0.710 & 4.21 \\
\hline R1234yf & 25.0 & 0.62 & 0.810 & 3.41 \\
R1234ze(E) & 26.1 & 0.58 & 0.744 & 2.75 \\
R1233zd(E) & 28.5 & 0.47 & 0.595 & 0.81 \\
& Propane (Figure 6, A3) & 23.0 & 0.77 & 0.926 & 7.37 \\
Isobutane & 25.0 & 0.61 & 0.807 & 2.75 \\
& Propylene & 22.7 & 0.80 & 0.931 & 8.95 \\
R134a & 25.9 & 0.62 & 0.745 & 3.81 \\
R245fa & 29.0 & 0.44 & 0.575 & 0.94 \\
R152a & 25.5 & 0.65 & 0.754 & 4.41 \\
\hline R1234yf & 23.8 & 0.57 & 0.732 & 3.14 \\
R1234ze(E) & 24.8 & 0.52 & 0.659 & 2.48 \\
R1233zd(E) & 27.0 & 0.39 & 0.494 & 0.68 \\
Propane & 21.8 & 0.71 & 0.856 & 6.91 \\
Geom 3obutane & 23.9 & 0.55 & 0.725 & 2.51 \\
Propylene & 21.6 & 0.75 & 0.864 & 8.41 \\
R134a & 24.5 & 0.55 & 0.665 & 3.46 \\
R245fa & 27.8 & 0.36 & 0.468 & 0.77 \\
R152a & 24.2 & 0.59 & 0.676 & 4.00 \\
\hline
\end{tabular}
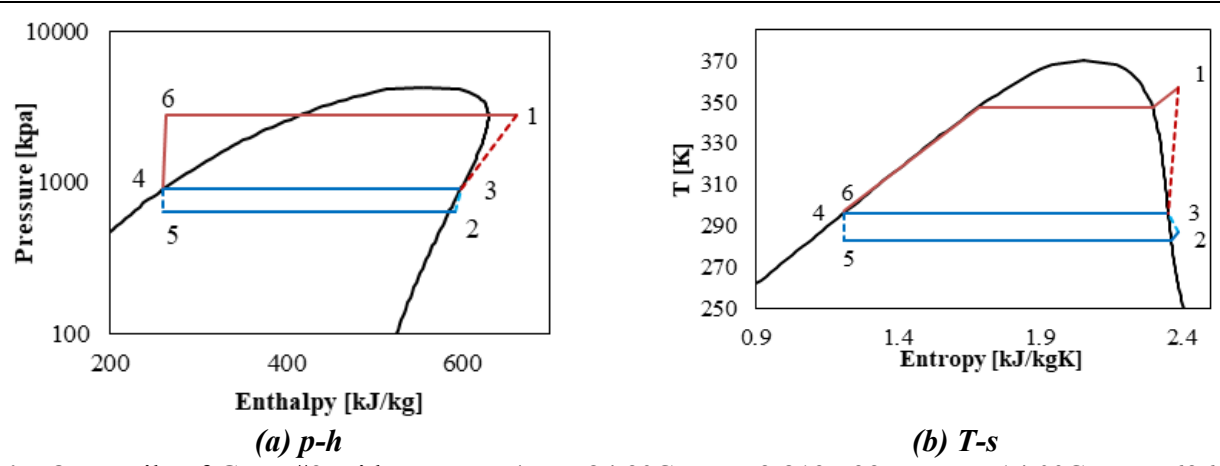

Fig. 8. Details of Geom\#2 with Propane $\left(T_{1}=84.2{ }^{\circ} \mathrm{C}, P_{1}=2,813,532 \mathrm{~Pa} T_{2}=14.0^{\circ} \mathrm{C}, P_{2}=636,601\right.$ $\mathrm{Pa} T_{3}=23^{\circ} \mathrm{C}, P_{3}=904,508 \mathrm{~Pa}$ ). 


\section{Conclusions}

This paper contributes to the present-day discussion regarding multi-scale modeling approaches: to this end, the COP of an ERS is evaluated using a lumped parameter model, using as input data the results provided by $C F D$ simulations. Three ejector geometries (changing the nozzle exit position from a baseline case) have been tested with third (R134a, R245fa, R152a) and fourth generation/natural (R1234yf, R1234ze, R1233zd, R290, R600a $\mathrm{R} 1270)$ refrigerants. The results showed that refrigerants could be grouped in three main categories; (i) propane and propylene, having higher COP values (approximately 0.8) but lowers $T_{\text {crit }}$ approximately $\left(22.5^{\circ} \mathrm{C}\right)$. (ii) R1234yf, R1234ze and isobutane, providing similar results compared with $\mathrm{R} 134 \mathrm{a}$ and $\mathrm{R} 152 \mathrm{a}$ (COP approximately equal to $0.57 ; T_{\text {crit }}$ approximately equal to $24.8^{\circ} \mathrm{C}$ ). (iii) $\mathrm{R} 1233 \mathrm{zd}$ exhibited the lowest performances $(C O P$ approximately equal to 0.43 ) but higher $T_{\text {crit }}$, approximately equal to $27.8^{\circ} \mathrm{C}$. It is also noted that reducing $N X P$ improves both $C O P$ and $T_{\text {crit }}$. In conclusion, the present outcomes pose a step forward in refrigerant selections.

\section{Acknowledgments}

This work has been financed by the Research Fund for the Italian Electrical System in compliance with the Decree of Minister of Economic Development April 16, 2018.

\section{References}

1. G. Besagni, R. Mereu, F. Inzoli, Ejector refrigeration: A comprehensive review, Renew. Sustain. Energy Rev. 53, 373-407 (2016)

2. B.M. Tashtoush, M.A. Al-Nimr, M.A. Khasawneh, A comprehensive review of ejector design, performance, and applications, Appl. Energy. 240, 138-172 (2019)

3. Z. Aidoun, K. Ameur, M. Falsafioon, M. Badache, Current advances in ejector modeling, experimentation and applications for refrigeration and heat pumps. Part 1: Single-phase ejectors, Inventions. 4(1), 15 (2019)

4. Directive 2006/40/EC of the European Parliament and of the Council of 17 May 2006 relating to emissions from air conditioning systems in motor vehicles and amending Council Directive 70/156/EC, (2006).

5. A. Cavallini, The state of the art on Refrigerants, (n.d.).

6. A.K. Yadav, Neeraj, Performance Analysis of Refrigerants R1234yf, R1234ze and R134a in Ejector-Based Refrigeration Cycle, Int. J. Air-Conditioning Refrig. 26(03), 1850026 (2018)

7. J. Chen, H. Havtun, B. Palm, Screening of working fluids for the ejector refrigeration system, Int. J. Refrig. 47, 1-14 (2014)

8. Y. Fang, S. Croquer, S. Poncet, Z. Aidoun, Y. Bartosiewicz, Drop-in replacement in a R134 ejector refrigeration cycle by HFO refrigerants, Int. J. Refrig. 77, 87-98 (2017).

9. I.H. Bell, J. Wronski, S. Quoilin, V. Lemort, Pure and pseudo-pure fluid thermophysical property evaluation and the open-source thermophysical property library coolprop, Ind. Eng. Chem. Res. 53(6), 2498-2508 (2014)

10. G. Besagni, F. Inzoli, Computational fluid-dynamics modeling of supersonic ejectors: Screening of turbulence modeling approaches, Appl. Therm. Eng. 117, 122-144 (2017)

11. E.W. Lemmon, M.L. Huber, M.O. McLinden, others, NIST standard reference database 23, NIST Ref. Fluid Thermodyn. Transp. Prop. Version. (2010). 
12. J. García Del Valle, J. Sierra-Pallares, P. Garcia Carrascal, F. Castro Ruiz, An experimental and computational study of the flow pattern in a refrigerant ejector. Validation of turbulence models and real-gas effects, Appl. Therm. Eng. 89, 795-811 (2015)

13. J. García Del Valle, J.M. Saíz Jabardo, F. Castro Ruiz, J.F. San José Alonso, An experimental investigation of a R-134a ejector refrigeration system, Int. J. Refrig. 46, 105-113 (2014) 